\title{
Hacia una perspectiva para la Cepalc en el siglo XXI
}

VÍCTOR L. URQUIDI 


\section{El Colegio de México}

Sin desear reabrir la polémica producida por Luis Alberto Sánchez en los años cuarenta con su "¿Existe América Latina?", Y mucho menos remontarme a la época de la gloriosa Independencia de las naciones latinoamericanos en el siglo XIX, quisiera más bien insistir en la evolución, durante los últimos 25 años, de los países comprendidos en la región llamada América Latina -ahora con el añadido del Caribe de naciones de esta subregión antes dependientes de potencias europeas-. Pensando sobre todo a futuro, cabe preguntarse si tiene sentido tratar en su conjunto, con cifras y conceptos de gran agregación, lo que hoy, en el lenguaje de Naciones Unidas se denomina «América Latina y el Caribe».

Me propongo hacer referencia en particular al alcance y la Función del CEPAL -hoy CEPALC-, organismo creado en 1948, a instancia sobre todo de Chile, en la Asamblea General de las Naciones Unidas.

Es de utilidad recordar dos hechos previos: la Conferencia Interamericana sobre Problemas de la Guerra y de la Paz de 1945 (Conferencia de Chapultepec) y, unos meses después, la importancia de la participación latinoamericana en la Conferencia de San Francisco en la que se suscribió la Carta de las Naciones Unidas. En algún momento se dio pie, sin mayor éxito, a la idea de que América Latina podría constituir un organismo regional en Naciones Unidas. Sin embargo, los gobiernos representados en la Unión Panamericana se adelantaron en abril de 1948, en Bogotá, proponiendo la conversión de este viejo organismo en una Organización de los Estados Americanos, con un Consejo Interamericano Económico y Social (CIES).

El Acta de Bogotá fue suscrita a pesar de haberse producido ya algunas fracturas en la tradicional solidaridad latinoamericana. Más adelante, surgieron otras en las Asambleas de la OEA, en relación con el régimen de Guatemala y el de Cuba. En el área económica se presentaron también diferencias en la Conferencia de Ministros de Hacienda efectuada en Quitandinha en 1954, a propósito de la propuesta de Chile de crear el Banco Interamericano de Desarrollo. Perú y Estados Unidos votaron en contra.

No obstante y, posiblemente, por las diversas tendencias políticas internacionales de la postguerra, y porque existían ya una Comisión Económica para Europa y una Comisión Económica para Asia y el Lejano Oriente, que reportarían al Consejo Económico y Social de las Naciones Unidas, prosperó en la Asamblea General la propuesta, ardua y exitosamente defendida por el representante chileno, Hernán Santa Cruz, de crear la CEPAL, dotada de una secretaría técnica integrada por personal de las Naciones Unidas, de por sí independiente de la influencia de cualquier potencia.

El resultado inicial más destacado de esta independencia se vio en las conferencias gene- 
rales del CEPAL de 1948 en La Habana y de 1950 en Montevideo, así como en la diferencia entre el primer Informe Económico sobre la Economía Latinoamericana en 1947, de corte más bien descriptivo y el Informe de 1949, de fondo analítico. De allí en adelante el CEPAL fue más importante y representativo que el CIES. Pero en 1951, como bien to ha relatado Celso Furtado en A Fantasía Organizada, peligró la vida del CEPAL, cuyo mandato inicial había sido de tres años; la conferencia en México ese año no había revelado una total identidad de propósitos entre los gobiernos latinoamericanos, inclusive el de México, a favor de continuar con el CEPAL, y se quiso hacer valer mucho la idea de que con el CIES bastaba. Brasil salvó al CEPAL. Por cierto, en esa conferencia los países centroamericanos mostraron su solidaridad para iniciar la integración económica del Istmo Centroamericano por medio de un Comité en que estarían representados los ministros de Economía y con apoyo en los servicios técnicos de la Secretaría del CEPAL.

Con referencia sólo a los hechos económicos y sociales más destacados, y teniendo en cuenta tanto el grado de industrialización como la amplitud de la cohesión social, es evidente -y así lo muestran los análisis recientes de la propia CEPALC- que las disparidades internas de la región, es decir, entre los 34 países que la componen formalmente, han aumentado considerablemente. Desde estos puntos de vista son varias las «Américas latinas y del Caribe». Dichas desigualdades son muy profundas, son difíciles de salvar -a diferencia de las convergencias de los miembros de la Unión Europea- y significan, de base, que las recetas generales que con frecuencia se ofrecen desde afuera a la región no tienen aplicación posible en todas partes o con el grado de similitud que en algunas esferas se supone pueda alcanzarse.

Cierto es que existen hoy algunas convergencias o tendencias semejantes entre algunos países de la región, por ejemplo en las transformaciones de los regímenes políticos en sistemas más democráticos o democráticos, por contraste con situaciones dictatoriales o autoritarias. Por lo demás, nunca ha dejado de haber similitudes culturales y lingüísticas, -salvo con el Caribe ex-británico o ex-holandés-, siempre recordando que en Haití se habla francés y creole, y que la lengua de los brasileños es el portugués, y que la «psicología» de los habitantes de las distintas naciones de habla hispana presenta algunas diferencias importantes.

Sin embargo, ante el hecho de la globalización reciente y actual, centrada en el comercio, las inversiones y las finanzas privadas, en la comunicación y la informática, se han acentuado mucho y se han vuelto más manifiestas las distintas capacidades de los países para tener acceso a los beneficios y defenderse de los inconvenientes de este nuevo proceso de alcance mundial. Lo cual se traduce en diferencias de poder económico relativo entre los principales países semi-industrializados de la región y los demás, y aún de regiones identificables dentro de cada país en su adaptación a la globalización. Al interior de los países, las regiones más adaptadas prosperan a costa de las más atrasadas. Algunos se agrupan en subregiones que, si 
llegaran a cooperar más efectivamente entre sí, tendrían más capacidad frente a los mercados internacionales que si actuaran por sí solos.

La fragmentación económica de América Latina data en particular del gran parteaguas que fue la sacudida del mercado petrolero mundial en 1973, que no fue debidamente prevista o que sólo un país, Venezuela, vio como, un proceso con una probabilidad positiva vía la OPEP. Los países de la región se dividieron, sin advertencia previa ni preparación alguna, en exportadores netos e importadores netos de petróleo crudo, estos últimos la mayoría, con efectos dispares y aún súbitos en sus economías, su comercio exterior, su competitividad, sus niveles de vida y sus finanzas.

Para los exportadores netos, a los que se agregó México en 1974, fue el surgimiento de una nueva y aumentada demanda externa, fuente de un alud de divisas. Para los importadores netos, fue un cambio desfavorable en los precios relativos con consecuencias diferenciadas en todos los sectores de producción y consumo, según fueran la elasticidades-precio de la demanda de energéticos, y más tarde las elasticidades-ingreso.

Para los exportadores netos fue también un potencial enorme de gasto de inversión para un desarrollo acelerado, pero a la vez para el dispendio en consumo (el «efecto Venezuela»), con frecuencia acentuado por monedas sobrevaluadas. Y respecto a los importadores netos fue necesaria una restricción forzada de ambas variables macroeconómicas, tanto la inversión pública y privada como el consumo público y privado.

Dada la penuria de recursos financieros a largo plazo del exterior, ambos grupos de países latinoamericanos recurrieron al crédito externo a plazos corto y mediano proveniente de la banca comercial de Europa, Norteamérica y Japón principalmente. Estos bancos canalizaron hacia América Latina y otras regiones buena parte de los petrodólares abundantes y disponibles para los gobiernos que quisieran usar esos créditos sin mayor restricción.

Este fue el segundo parteaguas, al producirse, hacia fines de 1981 y durante 1982, la gran crisis del endeudamiento excesivo que a su vez originó la suspensión del influjo de recursos externos.

La carga representada por el pago de intereses no tuvo compensación y surgieron amenazas de moratoria. Desde 1982, los países de la región, unos más que otros, se convirtieron en exportadores de una parte de su ahorro interno. La reducción consecuente de recursos para la inversión en desarrollo económico y social detuvo el crecimiento de la mayor parte de las economías de la región, afectando de manera negativa los programas de recursos humanos, el avance tecnológico y científico y el mejoramiento social. Además se produjeron muy fuertes desequilibrios fiscales, se generalizó la inflación, en algunos casos rayando en la hiperinflación, y se tuvo que reconocer el destino improductivo del gasto público. Se creó en distintos grados un malestar social antes desconocido. Fueron todos estos elementos los detonantes negativos para el desarrollo. 
En estas condiciones, con pocos casos de recuperación sólida, sobrevino el efecto de una globalización más aguda para la cual los países, en su mayoría, no estaban preparados ni siquiera para obtener dividendos de los elementos favorables que de ella pudieran derivarse. De ahí viene otra intensificación de diferencias. Hoy día sólo seis países -Argentina, Brasil, Colombia, Chile, México y Venezuela- han podido intervenir en escala apreciable en el gran mercado de la globalización y a la vez atraer mayor volumen de inversión extranjera directa, con el propósito de reorientar una parte de su producción manufacturera de sus mercados internos sobreprotegidos a los mercados externos de fuerte competitividad.

El resto de los países sigue dependiendo de la exportación de sus productos básicos tradicionales a los mercados internacionales inestables -azúcar, café y banano; petróleo, cobre y plomo; trigo y carne; algodón y oleaginosas- sin mayor aportación de productos manufacturados. Aun los países de gran exportación de manufacturas son asimismo proveedores de productos básicos a los mercados mundiales tales como petróleo, minerales, alimentos y fibras.

Con la pérdida tan aguda de lo que alguna vez fue cierta homogeneidad económica en la región latinoamericana, la agregación de los datos de 34 países para obtener cifras «de la región latinoamericana como un todo» no pasa de tener un simple interés geográfico convencional. Los totales agregados no dicen gran cosa, ni cuando suben ni cuando bajan, como tampoco significa mucho la consideración de sus tasas anuales de variación o la observación de los niveles absolutos. Esas cifras el PIB latinoamericano, la tasa de incremento del mismo, el coeficiente de inversión, las exportaciones y las importaciones, la inversión extranjera directa, los supuestos coeficientes de ahorro bruto para la región en su conjunto, dicen poco o nada que permita comprender los avances, los retrocesos y las vicisitudes de una región tan grande y heterogénea como es la latinoamericana.

Lo más grave es que la tradición que impera en «el resto del mundo» se caracteriza en todas las esferas, aún en los medios académicos, en tratar a «América Latina», sus datos, su evolución, como un todo, como región cuasi-homogénea, olvidando desde luego el «Caribe», que a su vez no es todo el Caribe. $Y$ en este sentido se hacen diagnósticos y se ofrecen recetas para salir de las crisis, promover el crecimiento, abrir los mercados al libre comercio, desregular y privatizar las economías, eliminar las «distorsiones de mercado» -o sea, los subsidios-, adoptar una rigurosa disciplina fiscal y dar mayor cabida a las nuevas inversiones de las empresas transnacionales sin ninguna restricción. En algunos casos hubo entradas de fondos a corto plazo, volátiles, a los llamados «mercados financieros emergentes», a fin de beneficiarse de las elevadas tasas de interés. Tales mercados carecían en casi todos los casos de verdadera solidez.

En la mayor parte de los países, ha transcurrido un plazo de más de 15 años sin que se haya podido generar un desarrollo social adecuado. La prioridad ha sido hacer frente a los compro- 
misos de deuda externa y tratar de atraer capitales. La educación, la ciencia y la tecnología, Ia salud, el mejoramiento urbano, el desarrollo rural se ha rezagado, en ciertas instancias en forma grave. Mientras tanto, la población de los países ha seguido aumentando con rapidez, si bien las tasas de natalidad han descendido ligeramente en algunos. La inercia demográfica ha dado lugar en muchos países a tasas de incremento de la fuerza de trabajo superiores a la tasa media de aumento de la población, tema que por lo demás requeriría analizarse en función de la distribución por edades.

Todo este conjunto de acontecimientos dispares ha menguado la solidaridad latinoamericana, ha afectado la autonomía económica y aún política y ha colocado a las autoridades financieras en el centro de decisión sobre el futuro de las economías sin suficiente consideración de los efectos acumulado del deterioro social y educativo. Tales deterioros no son fácilmente recuperables y debilitan la posibilidad de políticas comunes, sobre todo a escala regional completa. Los intentos de adoptar posiciones comunes sobre el endeudamiento externo en los años ochenta, lo demostraron con plenitud.

Además, los esquemas de integración regional y subregional, nunca demasiado sólidos ni de resultados espectaculares, se han debilitado y en ciertos períodos han dejado de actuar como instrumentos auxiliares del desarrollo comercial y de las inversiones. En condiciones de crisis, algunos de ellos prácticamente desaparecieron. En un caso, el de México, se dio al fin la espalda al resto de América L_atina para adherir a un convenio de libre comercio asimétrico con Estados Unidos y Canadá, que le reporta al país algunos beneficios, pero también lo abre a riesgos todavía no evaluados que pudieran ser desfavorables a largo plazo. El mercado de divisas para México no estaba en América Central y Sudamérica, sino en Estados Unidos.

En la mayor parte de los países de la región la capacidad y la voluntad del Estado para promover el desarrollo se han diluido. Lo que ha dejado de hacer el Estado no se ha compensado adecuadamente por el impulso que ha debido asumir el sector empresarial como un todo. Parte importante del sector empresarial consiste en pequeñas y medianas empresas con poca posibilidad de ir más allá de lo inmediato para la supervivencia. El desempleo y el subempleo han aumentado; han surgido nuevas formas de actividad de baja productividad y reducido ingreso en las grandes ciudades los sectores informales y ambulantes, que difícilmente podrán transformarse en empresas eficientes, mucho menos con capacidad para participar en los mercados externos.

En algunos países, las frecuentes crisis financieras, casi hechas a la medida por virtud de la desregulación bancaria y financiera, han conducido a la adopción de políticas monetarias de corto plazo que pretenden controlar la inflación por medios monetarios y deprimiendo la demanda interna sostenidamente. Estas soluciones monetarias, como en la gran depresión mundial de los años treinta, explican en gran medida el nuevo síndrome del crecimiento lento o nulo. Se carece de formulación de objetivos a largo plazo. 
Al CEPAL se atribuye haber diagnosticado como «decenio perdido» el de los años ochenta. En realidad en una perspectiva más amplia, se ha vivido en los últimos cien años un «siglo perdido», en que la región latinoamericana se rezagó, no sólo respecto a los países europeos y América del Norte, sino respecto a Japón y los países del sudeste de Asia.

Con la proximidad del siglo XXI, la mayoría de los países de la región latinoamericana y del Caribe tendrán necesidad de redefinir sus objetivos en función de la sociedad global y con referencia en particular a: i) una participación efectiva y eficiente en la economía global competitiva; ii) soluciones a largo plazo para los problemas estructurales internos que abarcan, por el lado de la oferta, las reformas democráticas, la educación y la capacitación, la innovación tecnológica, la capacidad empresarial y un nuevo papel activo para el disminuido Estado; y por el lado de la demanda, la construcción del mercado interno, la reducción de la desigualdad social y de ingresos familiares y el uso ambientalmente eficiente de los recursos. El desafío principal y central, por añadidura, será no sólo el desarrollo como antes se entendía sino el nuevo concepto de desarrollo sustentable, que abarca tanto la política ambiental como la corrección de las condiciones de desigualdad y exclusión.

Sin embargo, la transformación necesaria, como ya se venía insinuando en los informes de la CEPALC en los últimos años, requerirá, para lograrse con éxito, que se produzcan consensos políticos en los principales países, verdaderos pactos entre el Estado, los sectores empresariales y los obreros. Además, es probable que sólo puedan lograr esa transformación en forma adecuada los seis países semi-industrializados ya mencionados, igual que, como en épocas anteriores, fueron siempre los más adelantados. No es cuestión de una mera transición a un nuevo contexto de globalización bajo el impulso de «fuerzas del mercado» como quiera que éstas se definan. Bien puede preguntarse: ¿transición a qué? ¿cuál es el modelo a imitar? Deberá ser una transformación positiva e impulsada por el Estado y la sociedad civil conjuntamente, en un proceso de participación equitativa y democrática. Se requerirá que los sectores empresariales y privados asuman un nuevo papel con objetivos sociales y no sólo económicos y financieros de corto plazo. Se requerirá una nueva forma de coparticipación de empresas transnacionales o simplemente extranjeras que complementen el esfuerzo de las empresas nacionales.

Habrán de surgir nuevas formas de gobernación (governance) que hagan posible estas transformaciones. Se requerirá asimismo que la cooperación internacional asuma nuevas modalidades, tanto la que provenga del sistema de las Naciones Unidas, o la que ofrezcan los organismos financieros internacionales, las organizaciones multilaterales regionales, los agrupamientos subregionales o, por la vía bilateral, ciertos países del resto del mundo.

En la región latinoamericana el primer paso a dar para ingresar al siglo XXI debería ser abandonar la retórica todavía prevaleciente del siglo XIX, la memoria de los héroes de la 
independencia y más aún, el supuesto del siglo XX de que los problemas de la región puedan tratarse -ni siquiera medirse- como agregados. Siempre ha habido diferenciación, pero hoy es mucho mayor. No se ha asumido una preparación adecuada para el siglo XXI, ni siquiera para los próximos 20 años, teniendo en cuenta la evolución de la globalización, los cambios tecnológicos acelerados y la competitividad y la interacción globales. Por otro lado, ningún país de la región podrá actuar en forma aislada.

Si todo lo anterior tiene alguna validez, se ofrece a la CEPALC, con su experiencia y su dedicación, una oportunidad para colaborar de manera efectiva con grupos subregionales encabezados cada uno por alguno de los países de mayor desarrollo industrial. Los agrupamientos subregionales principales son el Mercosur, los restos del Pacto Andino, el endeble Mercado Común Centroamericano, la también débil comunidad del Caribe, pero no deben tratarse como bloques o islotes dentro de la región sino como puntos alrededor de los cuales pueda haber zonas de influencia en que países de menor desarrollo y menores capacidades, con la debida cooperación de los mayores, puedan participar a la vez de los beneficios de la integración subregional y de la globalización. Podrán darse casos en que países como Venezuela y Colombia cooperen con los del llamado Caribe, y también los centroamericanos con áreas del Caribe.

El caso mexicano es singular porque es el socio débil del Tratado Trilateral de Libre Comercio de América del Norte y sus perspectivas estân más vinculadas a mejorar su participación en el mismo, que es el más grande mercado externo para México, que a orientarse hacia las subregiones latinoamericanas, aunque no deba excluirse su acercamiento al Mercosur.

No se trata de llegar a pactos para crear mercados comunes o zonas de muy amplio e irrestricto libre comercio, sino de que las subregiones han de desarrollar la cooperación dentro de ellas, con potencial hacia el futuro, en materia de comercio, inversiones, transporte, programas de salud, educación y capacitación avances en ciencia y tecnología y en comunicaciones, y otras áreas. No basta suscribir convenios comerciales, ya que el comercio intrasubregional y el comercio de subcontratación sólo podrán desarrollarse bajo la base de mayor volumen recíproco de inversiones. Los tratados comerciales vacíos de contenido de inversión no constituyen incentivo suficiente.

La CEPALC, sin desatender su función dentro de las Naciones Unidas, podría dedicar mucha más atención a cooperar con los agrupamientos subregionales mediante comisiones o comités de consulta y cooperación específicos sobre temas concretos, a fin de fortalecer las zonas de influencia subregional, cooperar en la reducción de las disparidades y las asimetrías y ligar las actividades de esos agrupamientos con el mundo externo para, a su vez, ayudar a reducir las brechas entre los países de la región latinoamericana y los países industrializados de otras regiones del mundo, sea en lo individual o en sus propios respectivos agrupamientos 
como la Unión Europea, la APEC, y otros que puedan surgir. El modelo de la Comisión Económica de Europa en este sistema de cooperación, así como el de la Comisión Económica para Asia y el Pacífico, puede dar valiosas enseñanzas, sin perjuicio de las funciones más generales de la CEPALC. A su vez, la CEPALC debería hacer un esfuerzo para evitar generalizaciones excesivas sobre el conjunto de la región latinoamericana y para entrar en mayores análisis diferenciales de lo que se ha hecho hasta ahora.

Es necesario pasar del «siglo perdido» al siglo de las realizaciones, país por país, subregión por subregión, en interrelación con el contexto global creciente y cambiante. La CEPALC debería tener por misión fortalecer y auxiliar esta transformación. 